\title{
Multiple skalp ve ekstremite yerleşimli aplazia kutis konjenita
}

\author{
Aplasia kutis congenita with multiple scalp and limb locations
}

Işı Göğem İmren, Şeniz Duygulu, Hatice Meral Ekşioğlu

Gönderilme tarihi:21.03.2020

Kabul tarihi:27.07.2020

Özet

Aplazia kutis konjenita, deri, subkutan doku, seyrek olarak kemik ve meninkslerin yokluğu ile karakterize, nadir görülen heterojen bir hastalık grubudur. Tipik olarak aplasia kutis konjenita sporadik vakalar olarak görülmekle birlikte, sendromik vakalar da bildirilmiştir. Bu vaka sunumunda, 2 günlük bebekte multiple skalp derisi ve ekstremite defekti ile prezente olan sporadik bir aplasia kutis konjenita olgusu ile literatüründe seyrek rastlanan antiteyi skalp defektlerinin ayırıcı tanısında hatırlatmayı amaçladık

Anahtar kelimeler: Aplazia kutis konjenita, saçlı deri, konjenital defekt.

Göğem İmren I, Duygulu Ş, Ekşioğlu HM. Multiple skalp ve ekstremite yerleşimli aplazia kutis konjenita. Pam Tıp Derg 2021;14:267-270.

\begin{abstract}
Aplasia cutis congenita is a rarely seen heterogenous group of disease characterized by the absence of a portion of skin, subdermal tissue, infrequently bone and meninges. Aplasia cutis congenita is typically sporadic; however, syndromic cases have also been reported. In this report, we present sporadic case, two-day old baby who had multiple scalp and extremity defects. We aimed to remind the rare entity in differential diagnosis of scalp defects.
\end{abstract}

Key words: Aplasia cutis kongenita, scalp, congenital malformation.

Gögem Imren I, Duygulu S, Eksioglu HM. Aplasia kutis congenita with multiple scalp and limb locations. Pam Med J 2021;14:267-270.

\section{Giriş}

İlk defa 1976 yılında Cordon tarafından bildirilen aplazia kutis konjenita (AKK), Irk ve cinsiyet ayrımı olmaksızın 3/10.000 doğumda bir görülen non-inflamatuar, iyi sınırlı lezyonlarla karakterize nadir heterojen bir grup hastalıktır [1]. Tipik olarak sporadik vakalar görülmekle birlikte, otozomal dominant (OD) ve otozomal resesif (OR) geçiş de bildirilmiştir. Ribozomal GTPaz BMS1 mutasyonu OD vakalar ve UBA2 geninde missense mutasyonuyla ilişkilendirilen vakalar saptanmıştır [2, 3]. AKK genellikle tek lezyon olarak skalpte görülmekle birlikle (\%70); skalpte multiple, gövde ve ekstremite yerleşimli olanlar da vardır [4]. Epidermis ve üst dermise sınırlı lezyonlar hafif bir skar dokusuyla iyileşirken, subkutan doku, periost hatta dura materi içine alan defektler bildirilmiştir [5]. İzole benign natürde bir defekt olmakla birlikte konjenital anomaliler ve sendromların parçası olarak karşımıza çıkabilmektedir. Frieden 1986 yılında sayı, lokalizayon ve ilişkili durumları baz alarak AKK için 9 grupta incelenen bir klasifikasyon sistemi geliştirmiştir [6].

$\mathrm{Bu}$ vaka sunumunda multiple skalp ve ekstremite yerleşimli, malformasyonların ve teratojenik ilaç kullanımının eşlik etmediği sendromik olmayan sporadik bir vaka bildiriyoruz.

\section{Olgu sunumu}

22 yaşındaki annenin ilk gebeliğinden ilk yaşayan olarak normal spontan vajinal yolla 39 hafta 4 günlük olarak dünyaya gelen kız bebek, doğumda saçlı derisinde farkedilen lezyonlar için dermatoloji bölümüne 2 günlük iken konsulte edildi. Hastanın dermatolojik muayenesinde skalpte verteks yerleşimli 2 adet yan yana 10x8

Işıl Göğem İmren, Arş. Gör. Dr. Pamukkale Üniversitesi, Tıp Fakültesi, Dermatoloji Anabilim Dalı, Denizli, Türkiye, e-posta: isil.imren@gmail.com (orcid.org/0000-0002-9574-3231) (Sorumlu Yazar)

Şeniz Duygulu, Prof. Dr. Pamukkale Üniversitesi, Tıp Fakültesi, Dermatoloji Anabilim Dalı, Denizli, Türkiye, e-posta: senizergin@gmail.com (orcid. org/0000-0003-0426-6685)

Hatice Meral Ekşioğlu, Doç. Dr. Sağlık Bilimleri Üniversitesi Ankara Eğitim ve Araştırma Hastanesi Dermatoloji Kliniği, Ankara, Türkiye, e-posta: meral_eksioglu@yahoo.co.uk (orcid.org/0000-0003-0172-4548) 
$\mathrm{mm}$ çapında ülser ve bu lezyonların yanında $3 \times 3 \mathrm{~mm}$ boyutunda üzeri hemorajik kurutla kaplı erozyon gözlendi. Lezyon zemininde kemik doku palpe ediliyordu (Resim 1). Bebeğin sol ayak dorsal yüzünde medial metatarsal bölgeden başparmak proksimaline doğru uzanan $15 \times 10 \mathrm{~mm}$ boyutunda epitelyal defekt izlendi (Resim 2). Hastanın fizik muayene bulguları olağandı, sendromik bulgu saptanmadı. Vücut ağırlık, boyu ve baş çevresi 25-50 persantil aralığındaydı. Anne baba arasında akrabalık bulunmayan hastanın soy geçmişinde benzer saçlı deri defekti veya diğer genetik hastalık öyküleri bulunmamaktaydı. Doğum öncesi bakılan hepatit, TORCH serolojisinde pozitiflik saptanmayan annenin gebeliği sırasında metabolik, enfeksiyöz hastalık ve ilaç kullanım öyküsü bulunmamaktaydı. Annenin gebelik takipleri boyunca ve bebeğin postnatal olarak bakılan biyokimyasal ve hematolojik parametreleri normal sınırlar içerisindeydi. Sol ayak direk grafisinde ve kraniyal MR görüntülemesinde beyin parankiminde ve kemik yapılarda defekt izlenmedi. Nöroşirurji ve plastik cerrahi tarafından operasyon düşünülmeyen hastaya klorheksidinli pansuman ile yakın poliklinik takibi önerildi.

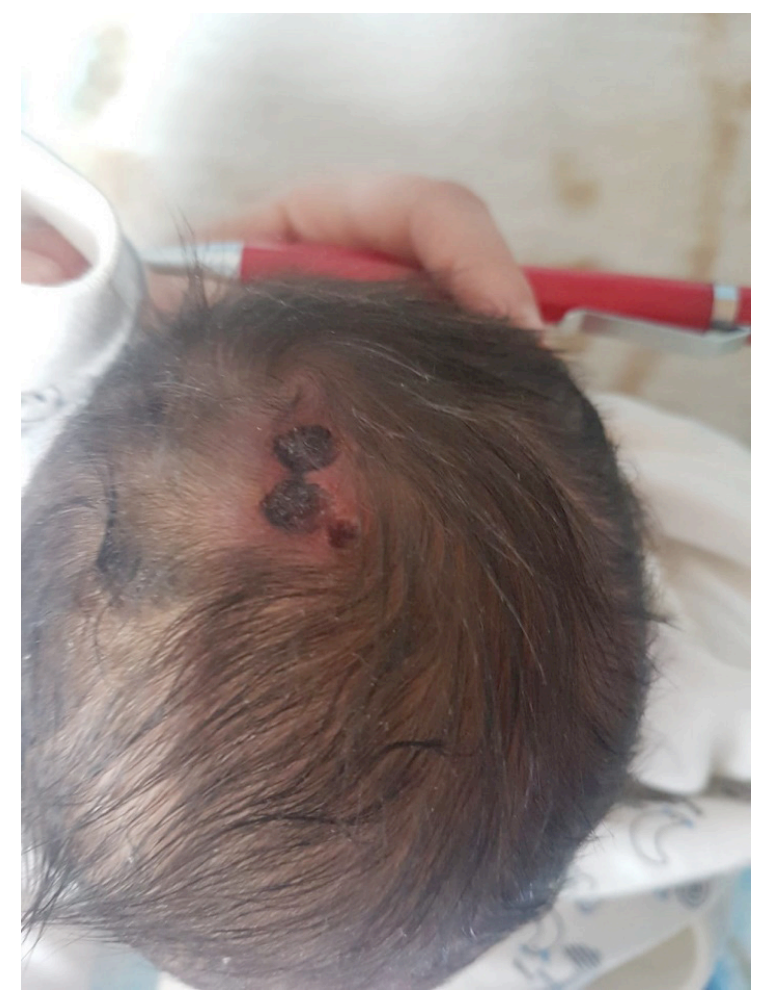

Resim 1. Skalpte verteks yerleşimli 2 adet yanyana 10x8 $\mathrm{mm}$ çapında ülser ve bu lezyonların yanında $3 \times 3 \mathrm{~mm}$ boyutunda üzeri hemorajik kurutla kaplı erozyon

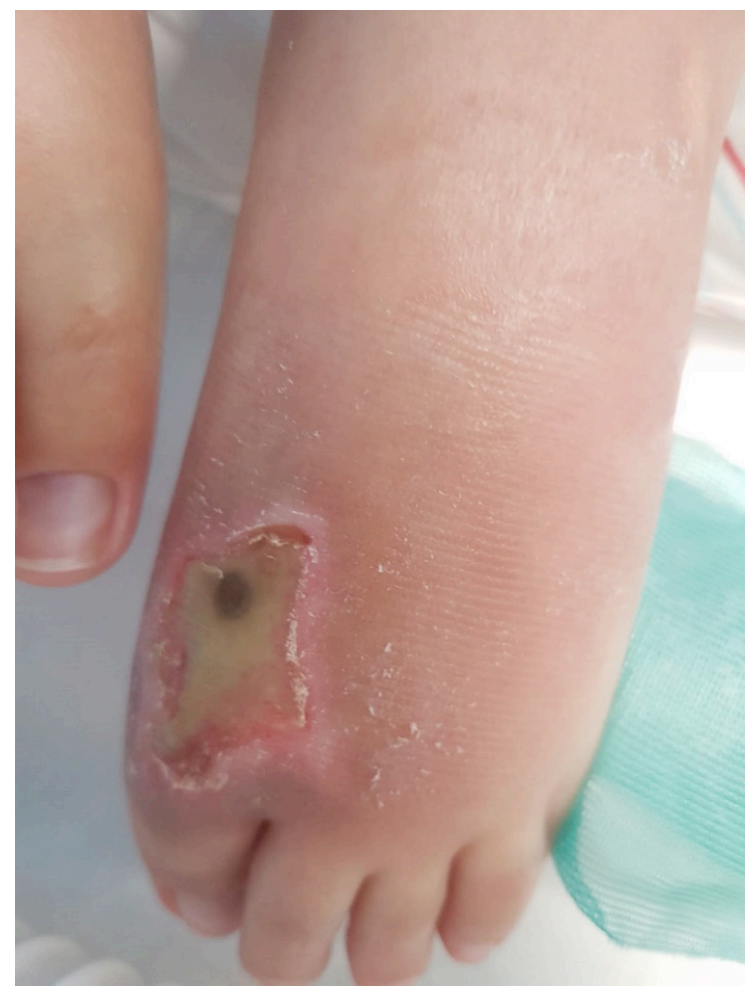

Resim 2. Sol ayak dorsal yüzünde medial metatarsal bölgeden başparmak proximaline doğru uzanan $15 \times 10 \mathrm{~mm}$ boyutunda epitelyal defekt

\section{Tartışma}

Hastalığın patofizyolojisinin tek bir teoriyle açıklanamamasıyla birlikte görülen fenotipik varyantlar birçok etken ve olayın farklı şiddette yansımaları olarak değerlendirilebilir. İntrauterin hayatta deri vaskülaritesini etkileyen travma, genetik, metabolik nedenler ve annenin gebelikte anjiyotensin dönüştürücü enzim inhibitörü, mizoprostol, valproat, metimazol gibi teratojenik ilaç kullanımının bu duruma sebep olabileceği gibi, tartışılan bir diğer durum ise 10-15. gestasyonel haftalarda nöral dokunun hızlı büyümesinin yarattığı gerilimle defektlerin meydana geldiği görüşüdür. Lezyonların bu gerilime en çok maruz kalan yer olan vertekste en sıklıkla görülmesi bu görüşü desteklemektedir [2]. Özellikle ekstremitelerde görülen lezyonlar için ise amniyotik membranın erken rüptürü ve intrauterin bantlar sorumlu gösterilmektedir. Aplazia kutisin membranöz ve büllöz varyantları ise nörol tüp defektlerinin bir varyantı olduğu ileri sürülmüştür. Genellikle deride sınırlı vakalar bildirilmesine rağmen $\% 20-30$ olguda alttaki kemik ve dura mater etkilenmiştir ve bu vakalarda süperior sagittal 
sinüse kanama, menenjit gibi hayatı tehdit eden komplikasyonlar gelişebilmektedir [5]. Frieden'in geliştirdiği klasifikasyon sistemine göre AKK vakaları 9 gruba ayrılmıştır (Tablo 1) [6].
Bizim vakamızda benzer aile öyküsünün olmaması, genetik hastalık risk faktörleninin bulunmaması, konjenital malformasyona ve sendromik bulgulara rastlanmaması

Tablo 1. Frieden AKK sınıflandırması, eşlik eden anomaliler

\begin{tabular}{|c|c|c|}
\hline Grubu & Eşlik eden bulgular & Kalıtım \\
\hline 1.Eşlik eden anomalinin olmadığı skalp AKK & & OD, sporadik \\
\hline 2. Ekstremite anomalileri ile beraber skalp AKK & $\begin{array}{l}\text { Adam's-Oliver sendromu,distal } \\
\text { falansların hipoplazi ve aplazisi }\end{array}$ & OD \\
\hline $\begin{array}{l}\text { 3. Epidermal veya organoid (Kelime hatalı) } \\
\text { nevüslerle birlikte AKK }\end{array}$ & $\begin{array}{l}\text { Nörolojik ve oftalmik } \\
\text { abnormalitelerle birlikte olabilir. }\end{array}$ & Sporodik \\
\hline 4. Embriyonik malformasyonlarla birlikte AKK & $\begin{array}{l}\text { Omfalosel, gastroşizis, } \\
\text { kraniosinostozlar, nöral tüp } \\
\text { defektleri, } \\
\text { Leptomeningeal anjiomatozis }\end{array}$ & $\begin{array}{l}\text { Altta yatan hastalığın kalıtım } \\
\text { durumuna bağlı }\end{array}$ \\
\hline $\begin{array}{l}\text { 5. 'Fetus papareseus' veya plasental enfaktlar ile } \\
\text { birlikte AKK }\end{array}$ & $\begin{array}{l}\text { Çoğul gebeliklerde fetüslerden } \\
\text { birinin intrauterin ölüm öyküsü } \\
\text { olabilir. }\end{array}$ & Sporadik \\
\hline 6.Epidermolizs bülloza $(E B)$ ile birlikte AKK & $\begin{array}{l}\text { EB simplex,distrofik ve junctional } \\
\text { ile birliktelik }\end{array}$ & EB kalıtım tipine göre \\
\hline 7. Ekstremitede büllerin eşlik etmediği AKK & & OD,OR, sporadik \\
\hline $\begin{array}{l}\text { 8. Teratojenlerle ilişkili AKK( ilaçlar ve enfeksiyöz } \\
\text { hastalıklar) }\end{array}$ & $\begin{array}{l}\text { HSV, VZV ve enfeksiyon } \\
\text { Metimazol, karbamezapin, } \\
\text { misoprostol ve diğer ilaç öyküleri }\end{array}$ & Kaltımsal değil \\
\hline 9. Malformasyon sendromları ile birlikte AKK & $\begin{array}{l}\text { Trisomi } 13 \text {, } \\
\text { Wolf-Hirschhorn, Goltz, Delleman } \\
\text { Sendromları ve daha birçok } \\
\text { sendromun komponenti olarak }\end{array}$ & $\begin{array}{l}\text { Sendromun kalıtım şekline } \\
\text { göre }\end{array}$ \\
\hline
\end{tabular}

*Tabloda tüm referanslardan yararlanılmıştır

ve enfeksiyon ve ilaç açısından şüpheli gestasyonel öykü bulunmaması sebebiyle Frieden sınıflandırması grup 1 ve grup 7'nin overlap şekilde bulunduğu sporadik bir vaka olarak değerlendirildi [6]. Multiple verteks defektinin yanında sol ayak dorsumunda epitelyal defektinin de bulunması intraüterin amniyotik bant gelişmiş olabileceği ve izole olarak ekstremitenin bu bölümünü yüzeyel şekilde etkilemiş olabileceği düşünüldü. Hasta parafine emdirilmiş klorheksidinli pansumanla yakın poliklinik takibine alındı.

$\mathrm{Bu}$ olgu sunumunda, sporadik vakalar görülebileceği gibi AKK'nin birçok konjenital malformasyonla birlikte görülebileceğine ve sendromların parçası olabileceğine dikkat çekmek istedik. Konjenital skalp defekti olan hastalarda ayrıntılı anamnez ve aile sorgusu altta yatan sebebin, morbidite ve mortalite riski içeren ilişkili durumların aydınlatılması açısından büyük önem arz etmektedir.
Yumuşak doku lezyonuna kemik defekti eşlik edip etmediği mutlaka görüntüleme yöntemleriyle açığa kavuşturulmalı, ilişkili olabilecek malformasyonlar açısından dikkatli fizik muayene yapılmalı ve düzenli izlemler planlanmalıdır.

Çıkar ilişskisi: Yazarlar çıkar ilişkisi olmadığını beyan eder.

\section{Kaynaklar}

1. Moros Peña M, Labay Matías M, Valle Sánchez F, Valero Adán T, Martín Calama Valero J, Muñoz Albillos M. Aplasia cutis congenita in a newborn: etiopathogenic review and diagnostic approach. An Esp Pediatr 2000;52:453-456.

2. Marneros AG. BMS1 is mutated in aplasia cutis congenita. PLoS Genet 2013;9:e1003573. https://doi. org/10.1371/journal.pgen.1003573 
3. Marble M, Guillen Sacoto MJ, Chikarmane R, Gargiulo $\mathrm{D}$, Juusola J. Missense variant in UBA2 associated with aplasia cutis congenita, duane anomaly, hip dysplasia and other anomalies: a possible new disorder involving the SUMOylation pathway. Am J Med Genet A 2017;173:758-761. https://doi.org/10.1002/ ajmg.a.38078

4. Moriya J, Kakeda S, Korogi Y, Soejima Y, Urasaki E, Yokota A. An unusual case of split cord malformation. AJNR Am J Neuroradiol 2006;27:1562-1564.

5. Burkhead A, Poindexter G, Morrell DS. A case of extensive Aplasia Cutis Congenita with underlying skull defect and central nervous system malformation: discussion of large skin defects, complications, treatment and outcome. J Perinatol 2009;29:582-584. https://doi.org/10.1038/jp.2008.250

6. Frieden IJ. Aplasia cutis congenita: a clinical review and proposal for classification. J Am Acad Dermatol 1986;14:646-660. https://doi.org/10.1016/S01909622(86)70082-0
$\mathrm{Bu}$ olgu sunumu poster bildiri olarak Uluslararası katılımlı 1.Bursa Dermatogenetik Sempozyumu'nda sunulmuştur.

Hasta onamı: Hastadan yazılı hasta onamı alınmıştır.

\section{Yazarların makaleye olan katkıları}

I.G.I. ve H.M.E. vakayı görüp ve klinik değerlendirmesini yapıp, poliklinikte takip etmişlerdir. Ş.D. ve I.G.I. vaka ile ilgili verilerin değerlendirmesini yapmışlardır. Olgu sunumunun yazımı I.G.I. tarafından yapılmış, tüm yazarlar gözden geçirip gerekli düzeltmeleri yapmış ve onaylamıştır. Ayrıca tüm yazarlar olgu sunumunu tartışmış ve son halini onaylamıştır. 